\title{
Paroxysmal extreme pain disorder
}

INSERM

\section{Source}

INSERM. (1999). Orphanet: an online rare disease and orphan drug data base.

Paroxysmal extreme pain disorder. ORPHA:46348

A rare, genetic, neurological disorder characterized by severe episodic perirectal pain accompanied by skin flushing that is typically precipitated by defecation. Ocular and submaxillary pain, associated with triggers including cold or other irritants, may become more prominent with age. 